\title{
0 CAPITAL SOCIAL DAS EQUIPES EMPREENDEDORAS NASCENTES
}

\section{RESUMO}

O capital social tem sido considerado uma força impulsionadora no surgimento e crescimento de novas organizações. Esta pesquisa investiga os efeitos do capital social sobre os projetos de empresas nascentes, conduzidos por equipes empreendedoras. Usando uma amostra de 33 equipes empreendedoras nascentes, o estudo explora: 1) a estrutura social interna da equipe, refletida pelos padrões de comunicação e sentimentos entre seus membros; e 2) a estrutura social externa da equipe, refletida na diversidade de laços que seus membros mantêm com terceiros e que influencia no avanço de uma idéia para negócios. Concluiu-se que equipes com elevado capital social externo apresentam um desempenho superior, ao passo que os resultados empíricos não sustentaram que o capital social interno seja melhor para o desempenho da equipe.

\section{Natalia Weisz \\ Purdue University}

\section{Roberto S. Vassolo}

Universidad Austral

\begin{abstract}
Social capital has been regarded as a driving force in organizational emergence and growth. This research investigates the effects of social capital in nascent entrepreneurial projects carried out by entrepreneurial teams. By surveying 33 nascent entrepreneurial teams, this paper explores how 1) the internal social structure of the team, which reflects the communication patterns and the feelings between the members; and 2) the team's external social structure, which is based on the diversity of ties that the members of the team have with outside parties, impact the advancement of a business idea. It was found that teams with high external social capital have a higher performance, while the empirical results failed to support that high internal social capital was better for team performance.
\end{abstract}

PALAVRAS-CHAVE Capital social, equipes empreendedoras, desenvolvimento de planos de negócio.

KEY WORDS Social capital, entrepreneurial teams, business plan development. 


\section{INTRODUÇÃo}

O capital social desempenha um papel importante em todas as fases do ciclo empreendedor (Aldrich, 1999). Ele fornece um meio para a troca de recursos críticos necessários para a criação e o sucesso da organização. Empreendedores baseiam-se em suas redes sociais e constroem novas redes no processo de obtenção de conhecimento, recursos e apoio para seus projetos. Alguns estudos mostram como o capital social permite o acesso a recursos tangíveis, tais como capital físico e financeiro (Aldrich e Zimmer, 1986; Zimmer e Aldrich, 1987; Birley, 1985; Bates, 1997). Outros estudos ilustram como o capital social contribui para a emergência e o desenvolvimento de novos empreendimentos, ao permitir acesso a recursos intangíveis, tais como às informações críticas que permitem a identificação e a exploração de oportunidades (Hills, Lumpkin e Singh, 1997; Ardichvili, Cardozo e Ray, 2003; Davidsson e Honig, 2003); apoio emocional para se assumir o risco da atividade empreendedora (Bruderl e Preisendorfer, 1998), bem como o apoio para que se persista no desafio empreendedor (Gimeno et al., 1997); e para se obter legitimidade e endosso (Deeds et al., 1997; Delmar e Shane, 2001), que são cruciais no momento inicial de uma nova empresa.

A maioria desses estudos focaliza as estruturas de rede de um único empreendedor. No entanto, uma grande parte de novos empreendimentos é iniciada por equipes. Embora seja difícil determinar a quantidade exata de novos empreendimentos que são iniciados dessa forma, podemos ter algumas estimativas. Por exemplo, em um estudo com 2.994 empreendedores, membros da National Federation of Independent Business (Federação Nacional de Negócios Independentes), Cooper et al. (1990) indicaram que $30 \%$ deles mencionaram ter contado com a dedicação integral de parceiros nos momentos iniciais de seus negócios. No entanto, certos tipos de negócios têm uma probabilidade maior de serem iniciados por equipes. Por exemplo, Cooper (1986), ao revisar as pesquisas sobre empreendimentos em alta tecnologia, identificou que $70 \%$ dos fundadores começaram seus negócios com parceiros em regime de tempo integral de dedicação.

Contudo, o que importa sobre equipes não é apenas o fato de que elas iniciam uma grande quantidade de empreendimentos, mas também que esses empreendimentos são, em média, mais bem-sucedidos do que os iniciados por indivíduos isolados (Lechler, 2001; Cooper e Gimeno, 1992; Timmons, 1990). Empreendimentos criados por equipes influenciam, positivamente, a sustentabilidade, a lucratividade e o crescimento de novos negó- cios. Embora esse fato seja amplamente reconhecido pela literatura, não há estudos que investiguem, com base em uma abordagem fundamentada em uma teoria consistente, esse elevado desempenho a partir de uma abordagem do capital social.

Além disso, o principal argumento fornecido pelos pesquisadores para explicar as vantagens das equipes baseia-se nas agregações e complementaridades de pessoas que possuem características, conhecimentos, habilidades e competências diversas (Roure e Maidique, 1986; Vésper, 1990). Essa abordagem explica as vantagens de equipes a partir da perspectiva do capital social, mas tende a subestimar a dinâmica social envolvida no processo de criação e implementação de um empreendimento.

Embora sejam poucos, há alguns pesquisadores que se voltaram para os aspectos sociais dos empreendimentos liderados por equipes. Com relação a isso, muitos têm demonstrado que as redes sociais externas dos membros da equipe provêm os empreendedores com uma importante lista de contatos para o desenvolvimento e crescimento do empreendimento. Por exemplo, Eisenhardt e Schoonhoven (1996) estudaram 102 novas empresas de semicondutores e demonstraram como a rede social dos membros das diretorias era particularmente crítica para as empresas nascentes, já que não havia ainda tempo suficiente para que as redes institucionais de contato tivessem sido estabelecidas. Em particular, esses pesquisadores demonstraram como as equipes com membros bem relacionados, seja com antigos patrões ou por terem ocupado cargos de alto nível, formaram alianças de desenvolvimento de produtos em níveis mais elevados. Outro estudo que analisa o capital social externo da equipe é o de Grandi e Grimaldi (2003), que investiga como a intenção das equipes de fundadores de estabelecer relações com agentes externos e a freqüência de interação com esses agentes levam a uma probabilidade maior de sucesso de empresas iniciadas em universidades.

Outros estudiosos têm demonstrado que o capital social interno da equipe, que envolve o nível de interação social e o de confiança e afetividade entre seus membros, também afeta o desempenho dos novos empreendimentos. Por exemplo, Lechler (2001) estudou 183 empresas fundadas por equipes na Alemanha e demonstrou que a interação social interna entre os membros da equipe exerceu um papel crítico no desempenho do empreendimento. Além disso, Ensley et al. (2002) estudaram 70 novos empreendimentos e descobriam que a coesão das equipes da alta administração estava positivamente relacionada com o desempenho dos novos empreendimentos. 
A despeito do progresso representado por todos esses estudos, nenhuma investigação foi conduzida de maneira que considere os aspectos sociais tanto internos quanto externos das equipes de novos empreendimentos e que faça uso de abordagens teoricamente apropriadas. O propósito deste artigo é começar a preencher essa lacuna. Contudo, em vez de focar nas equipes empreendedoras que iniciaram um novo negócio de forma bem-sucedida, como o faz a maioria dos estudos, este artigo estuda as equipes que ainda estão no processo de criar um novo empreendimento. Ou seja, este estudo está focado nos empreendedores nascente que, em conjunto com outros empreendedores, estão dando passos em direção à criação de uma nova empresa (Reynolds e White, 1997). Operacionalmente, alguém se torna um empreendedor nascente quando se engaja em pelos menos duas atividades empreendedoras, como fazer um leasing do imóvel em que a empresa será instalada ou dos equipamentos, ou elaborar um plano de negócios (Reynolds e White, 1997; Reynolds, 1997). Uma equipe empreendedora nascente é constituída de duas ou mais pessoas que estão se engajando em atividades empreendedoras com o objetivo de começar uma nova empresa.

Portanto, esta investigação traz uma importante contribuição para a literatura sobre empreendedorismo e redes, visto que estuda o impacto das diferentes estruturas de redes sobre o desempenho das equipes empreendedoras nascentes. Em particular, estuda como a dotação inicial do capital social interno e externo da equipe empreendedora nascente depende de alguns aspectos do processo de gestação do empreendimento, e que podem levar ao sucesso do novo empreendimento. Especificamente, esta investigação analisa como isso pode desempenhar um papel crucial no desenvolvimento e na qualidade da idéia do negócio.

A seção seguinte apresenta a base teórica do estudo e suas hipóteses. Em seguida, apresentamos a metodologia aqui empregada, os resultados e as principais conclusões do estudo.

\section{BASE TEÓRICA}

Burt (2001), de uma maneira simplificada, descreve o capital social como uma metáfora sobre a vantagem. Com essa metáfora, ele tenta explicar que quando certas pessoas ou certos grupos de pessoas conseguem melhores resultados no sentido de receber altos retornos sobre seus esforços, é porque estão de algum modo mais bem interligados. Contudo, ele também reconhece que mecanismos contrastantes de rede definem de diferentes maneiras o que significa "estar mais bem interligado".

Adler e Kwon (2002), em um esforço para reconciliar as diferentes perspectivas sobre o que significa estar mais bem interligado, revisaram a literatura sobre capital social e mostraram que a maioria dos estudos compreendem os seguintes focos: 1) as relações que um ator mantém com outros atores; 2) a estrutura das relações entre atores dentro de uma coletividade; ou 3) ambos os tipos de ligações. Eles descrevem que o primeiro grupo, que chamaram de "grupo de interligação", foca primariamente o capital social como um recurso inerente à rede social que liga um ator focal a outros atores. Nesse sentido, essa perspectiva está focada sobre como as ligações diretas e indiretas de um ator - isto é, uma pessoa, um grupo ou uma organização - com outros atores em redes sociais, facilitam seu sucesso em um contexto de rivalidade competitiva. O segundo grupo, que os autores denominaram de "grupo de compromisso", foca os benefícios que uma coletividade - ou seja, grupo, organização ou nação - obtém por meio das características internas de rede que lhe oferecem coesão e confiança e que, por esse motivo, facilitam a busca de um objetivo coletivo. Por fim, a terceira perspectiva, composta por estudos mais recentes - a saber, Nahapiet e Ghoshal (1998) - é neutra em termos da dimensão interna e externa.

Este artigo adota a categorização de Adler e Kwon (2002), concentrando-se no primeiro dos dois grupos. Nas páginas seguintes é feita uma descrição mais detalhada das abordagens da interligação e do compromisso. Baseando-se nessas abordagens, são sugeridas hipóteses específicas que relacionam cada uma dessas perspectivas ao desempenho dos projetos realizados pelas equipes empreendedoras nascentes.

\section{A perspectiva da interligação}

A perspectiva da interligação postula que o valor do capital social se origina da participação e do controle da difusão da informação. Essa perspectiva, dominada por Burt (1992) de "teoria dos vazios estruturais", descreve o capital social como uma função de oportunidades de intermediação. Ela enfatiza que o valor do capital social origina-se da interligação estrutural de vazios ou lacunas existentes entre os nós em uma rede social. Um vazio estrutural é definido como uma desconexão ou um relacionamento extremamente fraco entre dois contatos.

O trabalho de Burt (1992) fundamenta-se na teoria de Granovetter (1973) sobre a força de laços fracos. Sua 
fundamentação parte da descoberta sociológica segundo a qual a informação circula de forma mais intensa dentro dos grupos do que entre eles. Nesse sentido, o artigo clássico de Granovetter (1973) postula que laços fracos agem como "pontes" para as fontes de informação que não estão necessariamente contidas nos laços fortes de um indivíduo - sua rede imediata. Seu argumento é que os laços fortes de um ator serão conhecidos uns dos outros, mas que as relações casuais ou laços fracos permanecerão anônimos para seu "círculo íntimo". Portanto, as relações casuais têm uma probabilidade maior de fornecer uma informação única do que as amizades mais estreitas, não somente porque a maioria das pessoas possui laços mais fracos do que fortes, mas também porque os laços fortes têm uma probabilidade maior de receberem tipos similares de informação. Em outras palavras, a informação tende a ser relativamente redundante dentro de um dado grupo.

Burt (1992) elabora essas idéias e argumenta que uma rede esparsa, com poucos laços redundantes, fornece, em geral, maiores benefícios de capital social, visto que a oportunidade de intermediar o fluxo de informação entre os grupos constitui um benefício central do capital social. Ele argumenta que a presença de vazios estruturais entre grupos apresenta oportunidades para intermediar os fluxos de informação. Tais condições criam benefícios de informação, pois os atores que desenvolvem laços com grupos desconectados ganham acesso a um conjunto mais amplo de idéias e oportunidades do que aqueles que ficam restritos a um único grupo.

Em vista disso, a informação circula mais dentro dos grupos do que entre os grupos; uma fonte-chave do capital social é uma rede de laços caracterizados por muitos vazios estruturais e ligações com grupos que não estão conectados de outra forma. A presença de vazios estruturais ocorre em baixos níveis de densidade de rede, o que significa que o nível de conexão entre os atores na rede é baixo. Assim, de acordo com o argumento da interligação, níveis mais baixos de densidade de rede levam a níveis mais altos de capital social. Por sua vez, níveis mais altos de capital social levam a níveis mais altos de desempenho.

\section{A perspectiva do compromisso}

Em contraste com a perspectiva de capital social como um recurso localizado nas ligações externas do ator focal, a perspectiva do compromisso foca nas características internas dos atores coletivos. Nessa perspectiva, o capital social de uma coletividade não está propriamente nos laços externos dessa coletividade com outros atores, mas sim em sua estrutura interna - nas ligações entre indivíduos ou grupos dentro da coletividade e, mais especificamente, naquelas características que dão coesão à coletividade e, por esse motivo, facilitam a busca dos objetivos coletivos.

O trabalho mais citado dentro dessa perspectiva é o de Coleman (1988), que defende que o capital social é definido por sua função. Ele argumenta que tal capital não é uma entidade isolada, mas se refere a uma variedade de diferentes entidades, com dois elementos em comum: elas são constituídas por alguns aspectos da estrutura social, e facilitam certas ações dos atores - sejam atores individuais ou corporativos - dentro da estrutura. Coleman acredita que todas as relações sociais e estruturas facilitam certas formas de capital social. Contudo, certos tipos de estrutura social são especialmente importantes por facilitar algumas formas de capital social. A este respeito, ele argumenta que uma estrutura de rede densa - na medida em que os contatos dos atores são eles próprios conectados - fornece dois benefícios para os que pertencem a ela. Primeiro, afeta o acesso à informação. Observando que a qualidade da informação deteriora à medida que ela se desloca de uma pessoa para outra em uma cadeia de intermediações, mercados com redes de conexões mais diretas tendem a melhorar as comunicações. Segundo, facilita sanções que tornam menos arriscado para as pessoas na rede confiarem umas nas outras.

Coleman apresenta diversos exemplos para ilustrar os benefícios de redes densas, tais como associações de crédito rotativo, que não existiriam sem um alto nível de confiança entre os membros do grupo. Redes densas facilitam a emergência de normas eficientes e mantêm a confiança dos outros, reforçando, por esse motivo, o capital social. Em outras palavras, uma elevada densidade de rede dentro da coletividade tem a finalidade de fomentar a identificação, a comunicação e o nível de confiança mútua, o que facilita trocas e ações coletivas. Portanto, de acordo com a perspectiva do compromisso, níveis mais altos de densidade de rede resultam em níveis mais altos de capital social, que, por sua vez, resultam em níveis mais elevados de desempenho.

\section{Perspectivas contrastantes ou complementares?}

$\mathrm{O}$ fato de essas duas abordagens oferecerem predições contrastantes com relação à estrutura das relações sociais não implica necessariamente que sejam mutuamente excludentes ou independentes. Essas abordagens se diferenciam na medida em que focam aspectos diferentes das estruturas sociais e buscam resultados diferentes. Por 
um lado, o argumento do compromisso foca nos laços internos, ao passo que o argumento da interligação foca nos laços externos. Por outro lado, a primeira abordagem lança luz sobre os benefícios da solidariedade e da confiança, e a segunda nos benefícios da informação e do poder.

Embora nas pesquisa sobre capital social os pesquisadores tenham apresentado tendência a adotar ou a abordagem do compromisso ou da interligação, há alguns estudos que tentaram conciliar ambas. Esses estudos têm integrado os aspectos internos e externos, inter-relacionando unidades de análise (Reagans e Zuckerman, 2001; Burt, 2001). Laços externos, em um dado nível de análise, tornam-se laços internos em níveis de análise mais elevados e, de modo inverso, laços internos tornam-se externos em níveis mais baixos. Por exemplo, a ligação entre duas pessoas é externa em relação a cada um dos indivíduos; contudo, se esses indivíduos pertencerem a uma mesma equipe de trabalho, então essa ligação é interna à equipe. Esse é um avanço de grande importância, pois reconhece o fato de que a realidade das organizações é formada pela constante interação de relações sociais em diferentes níveis. Conseqüentemente, diferentes estruturas de rede não apenas coexistem, mas podem também ser complementares.

Este estudo, baseando-se nos estudos prévios que buscaram aproximar as duas perspectivas, direciona-se para ambos os pontos de vista - tanto sobre o da interligação externa como sobre o da vinculação interna para estudar o capital social das equipes empreendedoras nascentes.

\section{Hipóteses}

Tomando por base a abordagem da interligação e adaptando-a para um grupo e não para um empreendedor único, o desenvolvimento e a qualidade de uma oportunidade de negócio dependerá do capital social externo da equipe. Burt (1992) sugere que as oportunidades surgem de toda parte. Contudo, os benefícios de informação de uma rede definem quem conhece essas oportunidades, quando conhece e quem toma parte nelas. Portanto, um ator que estiver situado entre os elementos não conectados de uma rede terá maior chance de produzir uma idéia de negócio mais criativa e valiosa. Embora não existam estudos que analisem especificamente o desenvolvimento de idéias em um contexto empreendedor por meio da teoria dos vazios estruturais, com a exceção de Hills et al. (1997), há diversos estudos que usam esse argumento para demonstrar índices mais altos de inovação nas empresas (Ahuja, 1998; Stuart e
Podolny, 1996; Baum e Calabrese, 2000; Reagans e Zuckerman, 2001).

Quando uma equipe é composta por pessoas com um conjunto diverso de experiências, sua contribuição será variada e sua rede externa lhe dará acesso a um conjunto ainda maior de perspectivas e oportunidades. Uma equipe formada por pessoas com diferentes experiências terá maior probabilidade de desenvolver uma rede com laços mais heterogêneos. Assim, ela pode abarcar uma quantidade maior de vazios estruturais, e ter um acesso mais rápido a informações mais diversas e um controle maior sobre o significado da informação. Espera-se que esses fatores, que aumentam o capital social externo, tenham um impacto positivo sobre o desempenho da equipe.

Por outro lado, espera-se que as equipes com um capital social externo baixo, justamente aquelas que têm uma rede composta por laços homogêneos, gerem um desempenho inferior comparativamente as suas contrapartes com altos níveis de capital social externo. Isso acontece porque os laços homogêneos externos são de valor limitado para a equipe empreendedora nascente. À medida que os laços de pessoas do mesmo tipo se acumulam, o valor marginal de cada laço subseqüente cai. Laços de mais de uma pessoa com características similares ou em localizações sociais similares são redundantes e, assim, possuem um valor questionável em termos do fornecimento de novas informações (Burt, 1992).

Assim, temos:

Hipótese 1: Quanto maior o capital social externo de uma equipe empreendedora nascente, melhor será seu desempenho.

Com base na abordagem do compromisso e adaptando-a à equipe empreendedora nascente, o desenvolvimento e a qualidade de uma idéia de negócio também dependerá do capital social interno da equipe. A densidade de sua estrutura social interna cria seu capital social. A densidade de rede é a força média dos relacionamentos entre os membros da equipe. A força do relacionamento é normalmente representada pela freqüência de comunicação e pela eficiência entre os membros de um grupo. A densidade de rede é minimizada quando não existe relacionamento entre os membros da equipe, e é maximizada quando todos os membros estão ligados por meio de relacionamentos fortes.

Espera-se que um alto nível de densidade interna beneficie a equipe de diversas formas. Por um lado, sentimentos positivos entre os membros estimulam a confiança e a coesão dentro da equipe. Por outro, uma alta freqüência de 
comunicação entre os membros da equipe facilita a transferência de conhecimento e informação, o que é crítico para o processo de gestação de um novo empreendimento isto é, para o desenvolvimento de uma idéia de negócio.

Nesse sentido, estudos prévios, embora sem especificamente focar o desenvolvimento de uma idéia de negócio, têm citado a confiança como um elemento crítico, que melhora a qualidade dos fluxos de recurso (Larson, 1992a; Lorenzoni e Lipparini,1999), bem como a profundidade e riqueza das relações de troca, particularmente no que se refere à troca de informação e de conhecimento (Hansen, 1995; Uzzi, 1997).

Desse modo, temos:

Hipótese 2: Quanto mais alto for o capital social interno da equipe empreendedora nascente, melhor será seu desempenho

Em síntese, esta seção argumenta que ambas as estruturas sociais responsáveis pela criação de capital social podem agregar valor ao processo de gestação de um novo empreendimento. Uma equipe empreendedora estará melhor quanto maior for seu capital social interno e externo. Isso porque tanto a perspectiva do compromisso - que foca as relações internas da equipe - como a perspectiva da interligação - que foca as relações externas da equipe não são contrastantes entre si, mas complementares.

A densidade que existe na equipe desempenhará um papel significativo tanto ao realizar o valor das oportunidades presentes nos vazios estruturais (Burt, 2001) como ao transformar os conjuntos diversos de informação e perspectivas em melhores oportunidades de mercado. $\mathrm{O}$ argumento da interligação é então reforçado quando se dedica atenção à abordagem do compromisso, pois permite direcionar a atenção para a transformação e combinação de idéias e recursos à medida que fluem para os atores da rede. O argumento da interligação sozinho trata os atores da rede como condutores que repassam idéias imutáveis e recursos para outros. Ele coloca pouca atenção sobre como e porque esses conjuntos de informações, idéias e recursos são transformados e combinados em novas soluções por outros atores e subgrupos (Hargadon e Sutton, 1997).

\section{METODOLOGIA}

\section{Amostra}

A amostra deste estudo é formada por equipes empreendedoras nascentes que se registrou em uma competição nacional dos melhores planos de negócios chamada NA-
VES - Nuevas Aventuras Empresariales (Novas Aventuras Empresariais). O programa, que é realizado todo ano pela IAE, uma escola de Administração da Argentina, dura seis meses e tem como objetivo ajudar as equipes empreendedoras nascentes a desenvolver uma idéia de negócio, analisar a viabilidade dessa idéia e apresentar um plano completo de negócios. A universidade segue cada passo do processo a fim de que qualquer idéia promissora possa florescer até o estágio de levantamento de capital. O NAVES não é um mero exercício acadêmico, mas um programa em que equipes empreendedoras nascentes reais se inscrevem com o objetivo de dar partida a suas idéias e de reduzir, com o apoio e a instrução que o NAVES proporciona, a chance de fracasso de um novo projeto.

Com o intuito de assegurar que as equipes inscritas fossem realmente formadas por equipes empreendedoras nascentes reais, exigiu-se que todos os participantes respondessem às seguintes questões: "Independentemente de qualquer contingência desconhecida, se seu projeto NAVES se mostrar viável, você realmente tem a intenção de levá-lo até o fim?"; "Quão atrativa uma outra oportunidade de emprego precisaria ser para que você abandonasse a idéia de ter seu próprio negócio? Responda em uma escala que vai de 1 , para não atrativa, até 5 , para muito atrativa". Mais de $90 \%$ dos respondentes responderam à primeira questão afirmativamente, enquanto $86 \%$ responderam 4 ou 5 à segunda questão.

Embora essas respostas forneçam sustentação para a afirmação de que o NAVES não é um simples exercício acadêmico, há diversos outros aspectos que fornecem evidências adicionais para se acreditar que ele é um bom cenário para se conduzir esta pesquisa. Primeiro, o perfil das equipes participantes é bastante variado. Segundo, não há prêmios financeiros para os ganhadores da competição.

Para ilustrar a variedade de perfis das equipes, daremos alguns exemplos que não apenas mostram a variedade existente entre as equipes, como também na sua composição. A equipe vencedora da competição de 2001 era composta por um Ph.D em ciências, um acadêmico em biologia, um engenheiro de tecnologia de alimentação e um profissional com MBA - todos com aproximadamente 30 anos de idade -, enquanto a equipe vencedora da competição de 2002 era composta por seis homens, dos quais apenas um era estudante universitário. A média de idade da equipe era de 40 anos - o mais jovem tinha 23 anos e o mais velho, 56 anos. Esses exemplos dão uma idéia da diversidade de composição das equipes e, conseqüentemente, do potencial de diversidade nas estruturas de rede interna e externa entre as 
equipes, o que confirma que o NAVES é um excelente cenário para o estudo do capital social das equipes empreendedoras nascentes.

\section{Coleta de dados e índices de resposta}

Para a condução deste estudo pesquisamos as equipes empreendedoras nascentes registradas na competição NAVES 2002. Um mês depois de o programa ter sido iniciado, em junho de 2002, realizamos surveys para a obtenção de informações sobre cada um dos membros de todas as equipes empreendedoras. O objetivo foi obter informações a respeito das estruturas sociais internas e externas da equipe, dados demográficos de cada um dos membros, além de alguma informação sobre a idéia de negócios original que a equipe estava propondo. Fizemos um pré-teste do questionário para nos assegurarmos da validade das questões, medidas e linguagem.

Mais de 400 pessoas participaram, em uma amostra de 180 equipes empreendedoras. Recebemos respostas de 61 equipes, com pelo menos um membro respondendo cada questionário. Dessas 61 equipes, identificamos aquelas em que pelo menos um membro não respondeu ao survey. A amostra final compreendeu 33 equipes. Comparamos grupos completos com incompletos a fim de avaliar os vieses de não-resposta por meio de testes $t$. Não foram encontradas diferenças significativas.

A amostra final de 33 equipes foi composta por nove equipes de duas pessoas, nove de três pessoas, dez de quatro pessoas, uma equipe de cinco e quatro equipes de seis pessoas. A média de idade por grupo foi de 31 anos, com um desvio-padrão de oito pontos.

\section{MEDIDAS}

\section{Variável dependente}

A variável dependente refere-se à qualidade da idéia de negócios. Esta é uma variável discreta que avalia o nível de avanço da equipe na competição. A competição possui cinco estágios: registro, apresentação do plano de negócios preliminar, apresentação do plano de negócios, semifinal e final. A qualidade da idéia é medida de acordo com o avanço do plano de negócios na competição. O avanço do plano irá depender de a equipe apresentar ou não o plano de negócios e da avaliação que o júri fizer dos planos apresentados. O júri é composto de empreendedores, investidores, executivos e acadêmicos de Administração. Eles avaliaram aspectos relativos à idéia de negócios, tais como inovação, potencial de mercado, viabilidade, composição da equipe etc. Eles também avalia- ram o plano de negócios em diferentes estágios e decidiram se a idéia de negócios tinha potencial para continuar na competição ou se a equipe tinha de ser eliminada. Para evitar uma amostra desequilibrada, excluímos os níveis semifinal e final de avanço. Portanto, a variável dependente é discreta, com três categorias possíveis: "0", se a equipe se registrou para a competição, mas não foi adiante para desenvolver e apresentar um plano de negócios preliminar; "1", se a equipe apresentou o plano de negócios preliminar para ser avaliado pelo júri; e "2" se a equipe foi bem-sucedida em alcançar o estágio do projeto de negócios.

\section{Variáveis independentes}

Capital social externo. Medir o capital social externo da equipe é um desafio. Granovetter (1973), argumentando que os laços fracos agem como "pontes" que interligam as fontes de informação não necessariamente contidas dentro de uma rede individual imediata - laços fortes -, fornece uma excelente variável representante (proxy) para mediar a diversidade externa de rede da equipe. Como descrito na seção teórica, seu argumento é que os laços fortes tenderão a ser conhecidos entre as pessoas, mas os laços fracos permanecerão anônimos para o "círculo mais íntimo". Além disso, os contatos casuais têm uma probabilidade maior de fornecer informação única do que os amigos mais próximos, pois a maioria dos indivíduos tem mais laços fracos do que fortes. Assim, o conjunto de indivíduos constituído por qualquer indivíduo e seus contatos casuais compreende uma rede de baixa densidade, enquanto o conjunto constituído pelo mesmo indivíduo e seus amigos próximos será uma rede densamente entrelaçada. A primeira rede terá acesso a conjuntos diversos de informações e pontos de vista, ao passo que a segunda será mais homogênea.

Ao se transferir essa lógica para a equipe de empreendedores nascentes é esperado que a diversidade de rede externa da equipe dependa da composição da equipe em termos da força dos relacionamentos entre os membros antes de se iniciar o trabalho sobre o projeto. Assim, medimos a diversidade de rede externa da equipe usando uma questão sociométrica: perguntou-se aos membros da equipe sobre a frequêencia com que falavam uns com os outros antes de começarem seu projeto. Cada participante tinha de responder se ele (ou ela) se comunicavam diariamente, semanalmente, mensalmente, menos do que isso ou se nunca falavam com os membros da sua equipe antes de começar a trabalhar em seu projeto. Dessa forma, quanto mais eles interagissem antes de co- 
meçar a trabalhar sobre seu projeto, mais suas conexões externas seriam similares. A medida foi calculada como segue:

$$
\text { freqüência de comunicação } o_{k}=\frac{\sum_{i=1}^{N_{k}} \sum_{j=1}^{N_{k}} z_{i j k}}{N_{k}\left(N_{k}-1\right)}, j \neq i \text {, }
$$

em que: $z_{i j k}$ é a freqüência na qual o membro $i$ da equipe declara se comunicar com o membro $j$ da equipe, e $N_{k}$ é o número de díades da equipe $k$.

Capital social interno. Duas variáveis diferentes medem a densidade de rede: proximidade emocional e presença de laços familiares. Elas também são construídas usando-se dados sociométricos. A proximidade emocional mede o nível de afetividade emocional associado à interação entre os membros. É uma medida diádica calculada como segue: cada membro tem de responder sobre a força do relacionamento que tem com cada outro membro da equipe. As possibilidades eram "especialmente próximos", "próximos", "menos do que próximos" e "distantes". Assim, a medida da proximidade emocional foi construída como segue:

proximidade emocional $_{k}=\frac{\sum_{i=1}^{N_{k}} \sum_{j=1}^{N_{k}} E_{i j k}}{N_{k}\left(N_{k}-1\right)}, j \neq i$,

em que $E_{i j k}$ é a força do relacionamento que o membro $i$ da equipe declara ter com o membro $j$ da equipe, e $N_{k}$ é o número de díades da equipe $k$.

Outra medida usada para a densidade interna de rede é a presença de laços familiares dentro da equipe. Para isso, perguntou-se a cada membro se ele era parente de algum outro membro da equipe. Foi então calculado o número de díades na equipe que estavam ligadas por laços de família.

\section{Variáveis de controle}

Usamos três diferentes variáveis de controle. Primeiro, controlamos o tamanho do grupo, visto que se espera que a densidade da estrutura social interna dos grupos seja negativamente associada com o tamanho. Por outro lado, espera-se que a densidade externa da rede da equipe tenha um relacionamento positivo com o tamanho do grupo.

Segundo, controlamos o tempo - medido em meses em que a equipe estava trabalhando no projeto. Isso é necessário porque muitas das equipes que se inscreveram na competição NAVES estavam trabalhando em seus projetos antes de se registrarem no programa. Quanto mais tempo e energia a equipe tiver devotado à idéia de negócios, melhor desenvolvida seria a idéia.

Finalmente, controlamos o capital humano, medindo o nível médio de educação dos membros de cada equipe. Isso foi feito com base na premissa de que, quanto maior for o capital humano, maior será o impacto positivo sobre o desenvolvimento de uma idéia de negócios.

\section{RESULTADOS}

A Tabela 1 apresenta as estatísticas descritivas, e a Tabela 2 mostra os coeficientes do teste de correlação de Pearson. Observemos que, em geral, todas as principais co-variáveis apresentam um baixo coeficiente de correlação com a variável dependente e entre si. Vários relacionamentos merecem destaque. Primeiro, o tempo trabalhando juntos e a freqüência de comunicação estão positivamente correlacionados, confirmando a importância de se introduzir essa variável como uma variável de controle. Embora não descrita aqui, a proximidade emocional é alta e positivamente correlacionada com o desviopadrão de idade da equipe. Isso pode indicar a presença de familiares, como filhos e filhas, na composição da equipe. Em outras palavras, parece adequado considerar a presença de membros familiares na equipe como um representante da proximidade emocional. Também descobrimos que, quando há pelo menos uma díade na equipe, existe uma alta correlação com a freqüência de comunicação entre os membros antes de eles começarem a trabalhar no projeto.

A Tabela 3 mostra os resultados da análise de correlação para a qualidade da idéia de cada projeto empreendedor. O Modelo 1 inclui somente as variáveis de controle. Vemos que as equipes com o maior número de membros e que investiram mais tempo - medido em meses - no projeto têm um impacto positivo sobre o desempenho. De modo surpreendente, o nível educacional não parece nem aumentar nem reduzir o desempenho da equipe.

O Modelo 2 incorpora a medida da diversidade externa de rede a fim de testar a Hipótese 1. Essa hipótese, a qual afirma que, quanto maior for o capital social externo da equipe empreendedora nascente, melhor é seu desempenho, foi confirmada. A freqüência de comunicação antes de se iniciar o trabalho sobre o projeto teve um relacionamento significativamente negativo com a qualidade da idéia de negócios.

Os Modelos 3 e 4 incluem as variáveis de densidade interna de rede, a fim de testar a Hipótese 2. Essa hipóte- 
se, a qual afirma que quanto maior o capital social interno da equipe empreendedora, melhor é seu desempenho, não foi confirmada. A proximidade emocional medida em termos da afetividade entre os membros da equipe não foi significativa. Já a proximidade emocional medida em termos de laços familiares dentro da equipe foi significativa a um nível de 5\%, mas apresentou sentido contrário ao esperado.

O Modelo 5 incorpora as variáveis de controle, a medida do capital social externo e as variáveis do capital social interno. Observamos que os laços familiares perdem significância. Isso poderia ser devido à elevada correlação existente entre a presença de laços familiares em uma equipe e a frequência de comunicação.

\section{CONCLUSÕES}

Analisamos o efeito do capital social sobre o desempenho de equipes empreendedoras nascentes. Baseando- nos em pesquisas prévias sobre redes e equipes empreendedoras, identificamos duas hipóteses-chave, não exploradas. A primeira diz respeito ao efeito do capital social externo da equipe sobre o desenvolvimento da idéia de negócios. A segunda refere-se ao efeito do capital social interno da equipe sobre o desenvolvimento da idéia de negócios. Baseamos o estudo em uma amostra de 33 equipes empreendedoras nascentes que se inscreveram em uma competição de plano de negócios na Argentina.

Ao mesmo tempo em que ambas as hipóteses são derivadas de pesquisas prévias, os achados empíricos são, no mínimo, provocativos. Encontramos sustentação para a primeira hipótese, visto que as equipes com elevado capital social externo apresentaram um desempenho superior. Esse resultado, de acordo com a teoria dos laços fracos, indicou que uma elevada densidade de rede entre membros de equipes, antes de começarem a trabalhar sobre seus projetos, foi prejudicial para o desempenho da equipe.

Tabela 1 - Análise descritiva para a amostra.

\begin{tabular}{|l|c|c|c|c|c|}
\hline \multicolumn{1}{|c|}{ VARIÁVEL } & OBS. & MÉDIA & D.P. & MÍN. & MÁX. \\
\hline Qualidade da idéia de negócio & 33 & 1,36 & 0,78 & 0,00 & 2,00 \\
\hline Tamanho & 33 & 3,45 & 1,28 & 2,00 & 6,00 \\
\hline Tempo trabalhando juntos no projeto & 33 & 1,37 & 0,91 & 0,00 & 3,58 \\
\hline Nível educacional & 33 & 1,24 & 0,38 & 0,17 & 2,00 \\
\hline Proximidade emocional & 33 & 3,42 & 0,42 & 2,66 & 4,00 \\
\hline Laços familiares & 33 & 0,61 & 1,02 & 0,00 & 4,00 \\
\hline Freqüência de comunicação & 33 & 2,82 & 1,03 & 0,33 & 4,00 \\
\hline
\end{tabular}

Tabela 2 - Coeficientes de correlação de Pearson.

\begin{tabular}{|c|c|c|c|c|c|c|c|c|}
\hline & VARIÁVEL & $\begin{array}{l}\text { QUALIDADE DA } \\
\text { IDÉIA DE NEGÓcIO }\end{array}$ & 1 & 2 & 3 & 4 & 5 & 6 \\
\hline 1 & Tamanho & 0.2045 & 1.0000 & & & & & \\
\hline 1 & (1) & $(0.2537)$ & & & & & & \\
\hline 2 & & 0.2841 & -0.1399 & 1.0000 & & & & \\
\hline 2 & Iempo traoalnamao junios no projeto & (0.1090) & $(0.4375)$ & & & & & \\
\hline 3 & Nível educacional & 0.1833 & -0.0437 & -0.0304 & 1.0000 & & & \\
\hline & & $(0.3072)$ & $(0.8092)$ & $(0.8664)$ & & & & \\
\hline 4 & Proximidade emocional & 0.1025 & $0.3018^{\dagger}$ & $0.5911^{* * *}$ & -0.0927 & 1.0000 & & \\
\hline 4 & Proximinade emoctorial & $(0.5702)$ & $(0.0879)$ & $(0.0003)$ & $(0.6079)$ & & & \\
\hline 5 & Lacos de família & -0.2820 & 0.0216 & -0.0073 & 0.1594 & 0.0982 & 1.0000 & \\
\hline 5 & Laços de ramina & (0.1119) & (0.9049) & $(0.9676)$ & $(0.3756)$ & $(0.5868)$ & & \\
\hline 6 & Freqüência de comunicação & -0.2074 & -0.0535 & $0.4435^{* *}$ & $-0.3849 *$ & $0.3939 *$ & 0.1643 & 1.0000 \\
\hline & & $(0.2469)$ & $(0.7674)$ & $(0.0097)$ & $(0.0270)$ & $(0.0233)$ & $(0.3610)$ & \\
\hline
\end{tabular}

Nota: Níveis de significância entre parênteses: ${ }^{\dagger}$ significativo a $10 \%{ }^{*}$ significativo a $5 \% ;{ }^{* *}$ significativo a $1 \%$ 
Esses resultados podem sugerir que é exatamente no momento nascente, quando a formação da equipe é motivada pela proximidade entre os membros - laços de família, amizade, de colegas de estudo - e não por uma busca racional de parceiros complementares adequados, que as equipes têm a probabilidade mais alta de fracasso. Isso reafirma a descoberta de Ruef et al. (2002), de que a tendência que o empreendedor tem de evitar a inclusão de estranhos nas equipes fundadoras tende a diminuir a diversidade funcional e pode, no longo prazo, inibir o sucesso das novas organizações formais.

A segunda hipótese não foi confirmada. Os resultados empíricos não somente deixaram de sustentar que um elevado capital social interno era melhor para o desempenho da equipe, como também confirmaram uma causalidade significativamente oposta para uma de suas medidas - a existência de laços familiares.

A combinação dos resultados de ambas as hipóteses poderia sugerir que, em seu estágio nascente, se os processos de formação das equipes forem motivados pela proximidade entre os membros - laços familiares, amizade e colegas de estudo - e não por uma busca racional de parceiros complementares adequados, as equipes têm uma probabilidade maior de fracasso. Contudo, seria interessante estudar, com mais detalhes, o papel desempenhado pela proximidade emocional e pela confiança entre membros de equipes que estão no processo de gestação de um novo negócio. Os resultados obtidos neste estudo sobre esse aspecto são intrigantes.

\section{Limitações do estudo e pesquisas futuras}

Diversas limitações deste estudo devem ser destacadas. A primeira diz respeito ao tamanho da amostra. Tendo em vista que em estudos sobre redes um alto índice de respostas é crucial, tivemos de excluir aquelas equipes com baixo índice de resposta. Embora tivéssemos respostas de 61 equipes em que pelo menos um membro respondeu ao questionário, tivemos de selecionar apenas aquelas em que pelo menos três terços tivessem respondido à pesquisa, pois as medidas foram construídas de um modo diádico. Isso deixou-nos com uma amostra de 33 equipes empreendedoras nascentes. Mesmo que seja uma quantidade razoável de equipes, ainda não é ampla o bastante para a generalização dos resultados aqui encontrados.

A segunda limitação diz respeito à variável desempenho. Essa variável não considera a possibilidade de razões extraordinárias que as equipes poderiam ter tido para abandonar o programa. A informação sobre a existência de qualquer razão extraordinária daria maior confiança aos resultados.

A terceira limitação sugere uma área para pesquisas futuras. Sendo esse estudo trans-seccional, ele não permite uma avaliação extensiva do papel desempenhado pelo capital social interno no processo de desenvolvimento de um empreendimento. Um estudo longitudinal permitiria avaliar se as equipes que foram iniciadas com capital social interno - isto é, proximidade emocional baixo, mas que depois o aumentaram significativamente, estariam em melhor situação do que aquelas que ti-

Tabela 3 - Probabilidade máxima ordenada pela estimativa probit para a variável dependente Qualidade da Idéia de Negócio ( $\mathrm{N}$ = 33).

\begin{tabular}{|c|c|c|c|c|c|}
\hline VARIÁVEL & MODELO 1 & MODELO 2 & MODELO 3 & MODELO 4 & MODELO 5 \\
\hline \multirow{2}{*}{ Tamanho } & $0.599^{\dagger}$ & $0.700^{\dagger}$ & $0.603^{\dagger}$ & $0.671^{*}$ & $0.753^{\dagger}$ \\
\hline & $(0.337)$ & $(0.405)$ & $(0.349)$ & $(0.348)$ & $(0.408)$ \\
\hline \multirow{2}{*}{ Tempo trabalhando juntos no projeto (meses) } & $1.079 *$ & $1.582 *$ & $1.065^{\dagger}$ & $1.018^{*}$ & $1.366^{*}$ \\
\hline & $(0.518)$ & $(0.645)$ & $(0.621)$ & $(0.501)$ & $(0.708)$ \\
\hline \multirow{2}{*}{ Nível educacional } & 2.209 & $0.606^{\dagger}$ & 2.209 & $2.255^{\dagger}$ & 1.155 \\
\hline & (1.394) & (1.641) & $(1.390)$ & (1.251) & $(1.457)$ \\
\hline \multirow{2}{*}{ Freqüência de comunicação em T0 } & & $-0.939 *$ & & & $-0.849^{\dagger}$ \\
\hline & & $(0.512)$ & & & $(0.497)$ \\
\hline \multirow{2}{*}{ Proximidade emocional } & & & 0.455 & & 0.395 \\
\hline & & & $(1.099)$ & & $(1.144)$ \\
\hline \multirow{2}{*}{ Laços familiares } & & & & $-.7432^{\dagger}$ & -0.643 \\
\hline & & & & $(0.438)$ & $(0.432)$ \\
\hline Pseudo R2 & 0.14 & 0.199 & 0.14 & 0.188 & 0.237 \\
\hline Logaritmo de verossimelhança & -28.16 & -26.275 & -28.16 & -26.661 & -25.058 \\
\hline Teste da razão do logaritmo de verossimelhança & & $3.78^{*}$ & 0.00 & $3.01^{\dagger}$ & $6.22^{\dagger}$ \\
\hline
\end{tabular}

Notas: Desvios-padrão entre parênteses. Significância: ${ }^{\dagger}$ significativo a $10 \%$; * significativo a 5\%; ** significativo a $1 \%$. 
nham elevado capital social interno no exato primeiro momento da formação da equipe.

A rationale para isso é a seguinte: se o capital social interno das equipes for elevado desde o começo, isso implicaria que elas estivessem envolvidas nos mesmos ambientes sociais - ou em ambientes sociais similares -, o que reduziria suas chances de contribuir para o grupo com diferentes perspectivas, bem como com contatos sociais que poderiam fornecer informações críticas para realçar o desenvolvimento de sua idéia de negócios. Além disso, poderia haver uma troca entre o capital social interno e externo no início de um projeto. A questão desloca-se de uma perspectiva estática sobre uma dotação inicial de capital social interno e externo para uma perspectiva dinâmica sobre a gênese do capital social de uma dada equipe em suas condições iniciais. Estudos futuros poderiam analisar se é melhor para as equipes empreendedoras começarem com um capital social interno elevado e trabalharem depois no desenvolvimento do capital social externo; ou, pelo contrário, se é melhor começar com um capital social externo elevado e trabalhar depois para aumentar o capital social interno.

\section{REFERÊNCIAS BIBLIOGRÁFICAS}

ADLER, P; KWON, S. Social capital: prospect for a new concept. The Academy of Management Review, v. 27, n. 1, p. 17-40, 2002.

AHUJA, G. Collaboration networks, structural holes, and innovation: a longitudinal study. Administrative Science Quarterly, v. 4, n. 3, p. 425-455, 2000

ALDRICH, H.; ZIMMER, C. Entrepreneurship through social networks. In: SEXTON, D. L.; SMILOR, R. W. The art of science in entrepreneurship. Chicago: Upstart, 1986. p. 3-20.

ALDRICH, H. E. Organizations evolving. Thousand Oaks: Sage, 1999.

ARDICHVILI, A., CARDOZO, R.; RAY, S. A theory of entrepreneurial opportunity identification and development. Journal of Business Venturing, v. 18, n. 1, p. 105-123, 2003.

BATES, T. Financing small business creation: the case of Chinese and Korean Immigrant Entrepreneurs. Journal of Business Venturing, v. 12, n. 2, p. 109124, 1997

BAUM, J. A. C.; CAlabrese, T. Don't go it alone: alliance network composition and startups' performance in Canadian biotechnology. Strategic Management Journal, v. 21, n. 3, p. 267-294, 2000.

BIRLEY, S. The role of networks in the entrepreneurial process. Journal of Business Venturing, v. 1, n. 1, p. 107-117, 1985.
BRUDERL, J.; PREISENDORFER, P. Network support and the success of newly founded businesses. Small Business Economics, v. 10, n. 3, p. $213-$ 225, 1998.

BURT, R.. The network structure of social capital. In: SUTTON, R. I.; STAW, B. M. Research in organizational behavior. Greenwich: JAI Press, 2001.

BURT, R. S. Structural holes: the social structure of competition. Cambridge: Harvard University Press, 1992.

COLEMAN, J. S. Social capital in the creation of human capital. American Journal of Sociology, v. 94, p. S95-S120, 1988.

COOPER, A. C. Entrepreneurship and high technology. In: SEXTON, D. L.; SMILOR, R. D. The art of science of entrepreneurship. Cambridge: Ballinger, 1986. p. 153-168.

COOPER, A. C. et al. New business in America: the firms and their owners. Washington: National Foundation of Independent Businesses, 1990.

COOPER, A. C.; GIMENO, F. J. Entrepreneurs, processes of founding and new firm performance. In: SEXTON, D. L.; KASARDA, J. D. The state of the art of entrepreneurship. Boston: PWS-Kent, 1992. p. 301-340.

DAVIDSSON, P.; HONIG, B. The role of social and human capital among nascent entrepreneurs. Journal of Business Venturing, v. 18, n. 3, p. 301$330,2003$.

DEEDS, D. L. et al. The impact of firm-specific capabilities on the amount of capital raised in an initial public offering: evidence from the biotechnology industry. Journal of Business Venturing, v. 12, n. 1, p. 31-46, 1997

DELMAR, F; SHANE, S. Recombining, socializing, and legitimating: the selection of nascent ventures, 2000. (Working paper).

EISENHARDT, K. M.; SCHOONHOVEN, C. B. Resource-based view of strategic alliance formation: strategic and social effects in entrepreneurial firms. Organization Science, v. 7, n. 2, p. 136-150, 1996.

ENSLEY, M. D.; PEARSON, A. AMASON, A. C. Understanding the dynamics of new venture top management teams: cohesion, conflict, and new venture performance. Journal of Business Venturing, v. 17, n. 4, p. 365386, 2002.

GIMENO, J. et al. Survival of the fittest? Entrepreneurial human capital and the persistence of underperforming firms. Administrative Science Quarterly, v. 42, n. 4, p. 750-783, 1997.

GRANDI, A.; GRIMALDI, R. Exploring the networking characteristics of new venture founding teams. Small Business Economics, v. 21, n. 4, p. 329340,2003

GRANOVETTER, M. The strength of week ties. American Journal of Sociology, v. 78 , p. $1360-1380,1973$

HANSEN, E. Entrepreneurial networks and new organization growth. Entrepreneurship theory and practice, v. 19, n. 4, p. 7-19, 1995. 
HARGADON, A.; SUTTON, R. Technology brokering and innovation in a product development firm. Administrative Science Quarterly, v. 42, n. 4, p. 716-750, 1997.

HILLS, G. E.; LUMPKIN, G. T.; SINGH, R. Opportunity recognition: perceptions and behaviors of entrepreneurs. Frontiers of Entrepreneurship research, v. 17, p. 168-182. 1997.

LARSON, A. Network dyads in entrepreneurial settings: a study of governance of exchange relations. Administrative Science Quarterly, v. 37, n. 1, p. 76-104, 1992a.

LARSON, A. Partner networks: leveraging external ties to improve entrepreneurial performance. Journal of Business Venturing, v. 6, n. 3, p. 173-88, 1992b.

LECHLER, T. Social interaction: a determinant of entrepreneurial team venture success. Small Business Economics, v. 16, n. 4, p. 263-278, 2001.

LORENZONI, G.; LIPPARINI, A. The leveraging of interfirm relationships as a distinctive organizational capability: a longitudinal study. Strategic Management Journal, v. 20, n. 4, p. 317-338, 1999.

NAHAPIET, J.; GHOSHAL, S. Social capital, intellectual capital, and the organizational advantage. The Academy of Management Review, v. 23, n. 2 , p. 242-266, 1998.

REAGANS, R.; ZUCKERMAN, E. Networks, diversity, and productivity: the social capital of corporate R\&D teams. Organization Science, v. 12, n. 4, p. 502-517, 2001.

REYNOLDS, P. D.; WHITE, S. B. The entrepreneurial process: economic growth, men, women, and minorities. Westport: Quorum Books, 1997.

REYNOLDS, P. D. Who starts new firms? Preliminary explorations of firms in gestation. Small Business Economics, v. 9, n. 5, p. 449-462, 1997.
ROURE, J. B.; MAIDIQUE, M. A. Linking prefounding factors and high technology venture success: an exploratory study. Journal of Business Venturing, v. 1, n. 3, p. 201-220, 1986.

RUEF, M.; ALDRICH, H. E.; CARTER, N. M. With very little help from their friends: gender and relational composition of nascent entrepreneurs' startup teams. In: MEETING AT THE AMERICAN SOCIOLOGICAL ASSOCIATION. Chicago, 2002.

STUART, T. E.; PODOLNY, J. M. Local search and the evolution of technological capabilities. Strategic Management Journal, v. 17, p. 21-38, 1996.

TIMMONS, J. A. New venture creation: entrepreneurship in the 1990's. Homewood: Irwin, 1990.

UZZI, B. Social structure and competition in interfirm networks: the paradox of embeddedness. Administrative Science Quarterly, v. 42, n. X, p. 35-67, 1997

VÉSPER, K. H. New venture experience. Seattle: Vector Books, 1990.

ZIMMER, C. ALDRICH, H. Resource utilization through ethnic networks: kinship and friendship ties of shopkeepers in England. Sociological Perspective, v. 30, p. 422-445, 1987.

\section{NOTA}

Gostaríamos de agradecer às sugestões que recebemos de Arnie Cooper. Gostaríamos de fazer um agradecimento especial à Silvia Torres Carbonel e a Sebastián Inchauspe, do NAVES, por seu apoio constante para o desenvolvimento deste estudo.

Texto traduzido por Pedro F. Bendassolli.

Artigo recebido em 16.06.2003. Aprovado em 16.02.2004.

\section{Natalia Weisz}

Doutoranda pela Krannert School of Management da Purdue University. Interesses de pesquisa em teoria das organizações. E-mail: natalia_weisz@mgmt.purdue.edu

Endereço: Purdue University - 100 S Grant Street - West Lafayette, IN, 47907-2076.

\section{Roberto S. Vassolo}

Profesor do IAE - Universidad Austral. Doutor em Administração Estratégica pela Krannert School of Management da Purdue University. Interesses de pesquisa em teoria do conhecimento nas empresas, com ênfase no papel das alianças estratégicas no processo de exploração tecnológica.

E-mail: rvassolo@ iae.edu.ar 